\section{Development and Validation of Self-directed Learning Ability Test (SDLAT) for Elementary School Students}

Sooyeon Kimª, Kyunghwa Lee ${ }^{\text {b,* }}$

\section{Received: 30 January 2018 \\ Revised: 20 May 2018 \\ Accepted: $\quad 07$ June 2018 \\ ISSN: 1307-9298 \\ Copyright (C) IEJEE}

www.iejee.com

\begin{abstract}
The purpose of this study is to develop and validate self-directed learning ability test (SDLAT) for elementary school students considering the theoretical consistency. A total of 507 students of 5th and 6th-grade elementary students in Seoul, Korea were participated in this research. The collected data were analyzed using SPSS WIN 23.0 and AMOS WIN 22.0 programs. The data of 200 were used for exploratory factor analysis (EFA), and 307 data were used for confirmatory factor analysis (CFA). The conclusions were as follows: A SDLAT for elementary school students was developed and validated in this study. The domain of self-directed learning ability was classified into three domains of cognition, affective, and behavior. The sub-factors for each domain and 42 items were developed and then verified for its validity (NFI .824, IFI .906, CFI .905, RMSEA .043). The sub-factors of the cognitive domain were identified as 'cognitive thinking. metacognition' and 'problem solving'. The affective domain included 'intrinsic motivation', 'future-oriented motivation', and 'self-efficacy'. The behavioral domain had 'seeking help', 'managing physical environment', and 'time management'. The reliability of the total items of the test was Cronbach a .944.
\end{abstract}

Keywords: Self-directed learning ability (sdla), Validation of sdlat, Cognitive domain, Affective domain, Behavioral domain

\section{Introduction}

The education in the future should be able to grow talents that can adapt the fast-changing global knowledge information society. Therefore, the education of the future should focus on growing self-directed learning ability, insightful vision for future society, and ability to bring valuable outcomes in his/her own area through multi-faceted and creative thinking (Lee, 2017). Especially, amid rapid social changes, the self-directed problem-solving ability by using various resources and skills is receiving attention as a core competence (Kim, 2014). The self-directed learning ability that defined as a process in which students take the initiative to diagnose their needs, formulated learning goals, identify resources for learning, select and implement learning strategies, and evaluated outcomes is not limited to solving problems of a certain situation in everyday life, but also identifying what is needed for his/her own learning in terms of resource and strategy for learning. The self-directed learning has been termed differently, namely as independent learning, selfplan learning, self-teaching, autonomous learning, self-learning, and self-education (Guglielmino, 1977).

Knowles (1975) described self-directed learning as the ability to diagnose necessary tools for one's own learning, to identify human and other resources, to select and execute a proper learning strategy, and to evaluate the result without the help of others in the process. In contrast, Guglielmino (1977) described self-directed learning based on the characteristics of learners. First, they are independent and persistent in learning. Second, they have the responsibility for learning. Third, they view problems as challenges rather than obstacles. Fourth, they have a high level of discipline and curiosity. Fifth, they have a high desire for learning and change. Sixth, they have basic learning skills. Seventh, they can structure time and control the pace of learning. Eighth, they can develop a plan to finish a project. Ninth, they enjoy learning and tend to be goal-oriented. Brockett and Hiemstra (1991) divided the meaning of self-directed learning into two distinct but relevant dimensions. The first dimension is the process that assumes the learner has a fundamental responsibility in planning, implementing, and evaluating the course of learning. The second dimension is a self-directed aspect as a learner wants and prefers to learn by himself/herself.

In this regard, the self-directed learning can be defined as the learning process in which the learner takes responsibility for learning on his own and proceeds from the planning to execution and evaluation. In addition, the self-directed learning can be interpreted in two ways: the process of self-directed learning and the tendency of learners who shows self-directed ability.

Knowles (1975) emphasizes that self-directed learning is important in terms of short-term and long-term because it is a tragedy that learners do not know how to learn on their own. In other words, to achieve in the short term, active self-directed learners are more advantageous than passive learners, and self-directed learning is required in order to achieve educational objectives of research and technology development in the long term. Also from his point of view, education is not limited to school education, but rather lifelong learning that lasts a lifetime, so self-directed learning is more important. On the other hand, the necessary skills and competencies change according to changes in science and technology and social environment. Therefore, all learners no longer have to focus on knowledge-based education. In a future society where the scope of learning extends beyond the classroom to all aspects of life, the learner is no longer a passive learner, but is able to recognize what knowledge and information is needed. You need to know if there is. Therefore, learning method and learning ability appropriate to the educational situation are required from the existing learning method. 
The Korean Ministry of Education is also proposing self-directed learning ability as one of the core competencies that students must have achieved. As such, the self-directed learning is being emphasized as a core competency that must be constantly cultivated from elementary school students to adults in all curriculum courses. Recent studies of self-directed learning ability have revealed that the ability influences not only academic achievement but also various variables such as learner's relationship with peers, self-concept, happiness, learning motivation (Kim, 2014; Park, \& Choi, 2014; Ahn, \& Kim, 2014; Kim, Lim, \& Chung, 2015; Lim, \& Suh, 2017). In order to develop the self-directed learning ability, which is an important variable for successful learning and happiness of learners, it is necessary to develop and apply appropriate learning programs (Kim, 2004; Jung, 2004; Baik, 2011; S. R. Park, \& Son, 2017). Therefore, in order to develop and apply the program to improve self-directed learning ability, it is necessary to diagnose the starting point behavior of the learner first. Therefore, it is necessary to develop the test that can reliably and properly measure the self - directed learning ability.

Giglielmino (1977) developed a Self-Reported Self-Directed Learning Readiness Test (SDLRS) focusing on self-directed learners' tendencies, and Zimmerman and Martinez-Pons (1986) developed a test to reveal the strategic factors of self-directed learning. Oddie (1986) tried to measure the ability using standards that have three bipolar concepts.

The self-directed learning ability test in Korea was translated version of the test developed by Guglielmino (1977) for adults, or Zimmerman's self-regulated learning test tool for college students. They were not considered to the particular developmental stages of learners in Korea. However, there is an increasing effort to develop tools that take into account the characteristics of the culture and ages in Korea (Chung, 2002, 2003, 2005; Lee, Chang, Lee, \& Park, 2003; Song, 2005). However, there were not many researches to develop a test tool based on the component and the differentiation of the self-directed learning ability. Therefore, in this study, three domains of the cognitive, affective, and behavioral were set, and in each domain includes three sub-factors for development of self-directed learning ability test for elementary school students based on the test by Lee, Park, and Kim (2017) and precedent researches. The purpose of this study was to develop and validate self-directed learning ability test (SDLAT) for elementary school students considering the theoretical validity and consistency based on the 'self-directed learning ability test (SDLAT) for college students' developed by Lee et al. (2017).

\section{Method}

\section{Paticipants}

This study was conducted on 560 elementary school 5th and 6th-grade students in Seoul, Korea. 507 data were used for the analysis except for the 53 cases in which the response was insincere. The data of 507 were randomly divided for factor analysis, and 200 data were used for exploratory factor analysis, and 307 data were used for confirmatory factor analysis. Gender and grade distribution of all study participants are shown in Table 1 below.

\section{Measurement Scales}

Based on the components and test items of the SDLAT for college students developed by Lee, et al. (2017), we developed a preliminary question by modifying it or deleting unnecessary items according to the understanding level and characteristics of elementary school students. A total of 44 items were developed in three domains and nine sub-factors after the review of 15 specialists including educational psychologists and current elementary school teachers. The overall items of the preliminary questions are shown in Table 2 below.

Table 1. Participants

\begin{tabular}{|c|c|c|}
\hline \multicolumn{2}{|c|}{ Variables } & N (\%) \\
\hline \multirow{2}{*}{ Gender } & Male & $247(48.7)$ \\
\hline & Female & $260(51.3)$ \\
\hline \multirow{2}{*}{ Grade } & 5th & $240(47.3)$ \\
\hline & 6th & $267(52.7)$ \\
\hline \multicolumn{2}{|c|}{ Total } & $507(100)$ \\
\hline
\end{tabular}

Table 2. Preliminary Items

\begin{tabular}{|c|c|c|c|c|}
\hline Domains & Sub-factors & Items & $\begin{array}{c}\text { Item } \\
\text { Number }\end{array}$ & $\begin{array}{l}\text { Items } \\
\text { for } \\
\text { domain }\end{array}$ \\
\hline \multirow{3}{*}{ Cognitive } & $\begin{array}{l}\text { cognitive } \\
\text { thinking }\end{array}$ & 5 & $1 \sim 5$ & \multirow{3}{*}{15} \\
\hline & metacognition & 5 & $6 \sim 10$ & \\
\hline & $\begin{array}{l}\text { problem- } \\
\text { solving }\end{array}$ & 5 & $11 \sim 15$ & \\
\hline \multirow{3}{*}{ Affective } & $\begin{array}{c}\text { intrinsic } \\
\text { motivation }\end{array}$ & 5 & $16 \sim 20$ & \multirow{3}{*}{15} \\
\hline & $\begin{array}{c}\text { future- } \\
\text { oriented } \\
\text { motivation }\end{array}$ & 5 & $21 \sim 25$ & \\
\hline & self-efficacy & 5 & $26 \sim 30$ & \\
\hline \multirow{3}{*}{ Behavioral } & seeking help & 5 & $31 \sim 35$ & \multirow{3}{*}{14} \\
\hline & $\begin{array}{c}\text { managing } \\
\text { physical } \\
\text { environment }\end{array}$ & 4 & $36 \sim 39$ & \\
\hline & $\begin{array}{c}\text { time } \\
\text { management }\end{array}$ & 5 & $40 \sim 44$ & \\
\hline & Total & 44 & $1 \sim 44$ & 44 \\
\hline
\end{tabular}

Research Procedure

Based on the SDLAT for college students by Lee et al. (2017), 560 students from 5 elementary schools in Seoul were interviewed from January to February 2017. Of the 507 collected data, except for the data that was not responded in a satisfactory manner, 200 were randomly selected and used for the first exploratory factor analysis. After the first exploratory factor analysis, the items with the factor load that are less than 40 were reviewed by deleting or modifying items. The items were then carried out for second exploratory factor analysis. In the second exploratory factor analysis, a total of eight sub-factors, 42 items were chosen and confirmed. Afterwards, we verified the research model of three domains and eight sub-factors of the self-directed learning ability test through confirmatory analysis.

\section{Data Analysis}

The collected data were analyzed using SPSS WIN 23.0 and AMOS WIN 22.0 programs.To determine the internal consistency, Cronbach's coefficient alpha was computed. The appropriateness of the sample was verified with the value of KMO (Kaiser-Meyer-Olkin) and Bartlett's sphere formation test. The exploratory factor analysis results 
were analyzed by Principal Component Analysis and Orthogonal Rotation using Varimax. Maximum likelihood estimates were used for confirmatory factor analysis and fitness indexes such as CFI, NFI, IFI, and RMSEA were used for confirmatory factor analysis. The chi-square value and degree of freedom were considered in the model fit test. $\mathrm{CFI}, \mathrm{NFI}$, and IFI values were over .90(Hong, 2000), and the values within $.05 \sim .08$ were set as the standard for RMSEA based on Browne and Cudeck (1994). However, the fitness index is not absolute and should be judged relative to two or more degrees of fitness. (Hu., \& Bentler,,1998).

\section{Results}

In this study, for developing self-directed learning ability (SDLAT) for elementary school students, the ability was categorized in cognitive, affective, and behavioral domains. In addition, for each domain, three sub-factors were set. The cognitive domain includes 'cognitive thinking, metacognition, and problem-solving'. The affective domain has 'intrinsic motivation', 'future-oriented motivation, and 'self-efficacy'. The behavioral domain has 'seeking help', 'managing physical environment', and 'time management'. In order to identify the structure of the nine sub-factors in the three domains, we analyzed the inter-factor correlations, exploratory factor analysis (EFA), and confirmatory factor analysis (CFA).

\section{Inter-factor Correlations}

The result showed $.363-.702$ as it is shown in Table 3 for correlation between the nine factors for cognition, definition, and behavior domain of self-directed learning ability.

Table 3. Inter-factor correlations

\begin{tabular}{|c|c|c|c|c|c|c|c|c|c|}
\hline & 1 & 2 & 3 & 4 & 5 & 6 & 7 & 8 & 9 \\
\hline 1 & 1 & & & & & & & & \\
\hline 2 & $.645^{* *}$ & 1 & & & & & & & \\
\hline 3 & $.616^{\star *}$ & $.574 * \star$ & 1 & & & & & & \\
\hline 4 & $.568^{* \star}$ & $.535^{\star *}$ & $.527^{\star *}$ & 1 & & & & & \\
\hline 5 & $.508^{* \star}$ & $.455^{\star *}$ & $.412^{\star *}$ & $.577^{\star \star}$ & 1 & & & & \\
\hline 6 & $.643^{* *}$ & $.601 * \star$ & $.702^{\star \star}$ & $.629 * \star$ & $.479 * \star$ & 1 & & & \\
\hline 7 & $.509 * *$ & $.505^{\star *}$ & .491 ** & $.556^{\star *}$ & $.421 * *$ & $.540 * \star$ & 1 & & \\
\hline 8 & $.443^{* *}$ & $.439 * \star$ & $.374^{* *}$ & $.466^{\star *}$ & $.403^{* *}$ & $.462 * \star$ & $.363^{* \star}$ & 1 & \\
\hline 9 & $.567 * \star$ & $.546 * \star$ & $.462^{* *}$ & $.529 * *$ & $.410^{* *}$ & $.591 * \star$ & $.383^{* *}$ & $.531 * \star$ & 1 \\
\hline
\end{tabular}

** $p<.01$

Note: 1. Cognitive thinking 2. Metacognition 3. Problem-solving 4. Intrinsic motivation 5. Future-oriented motivation 6. Self-efficacy 7. Seeking help 8. Managing physical environment 9. Time management

\section{Exploratory Factor Analysis}

\section{Cognitive domain}

Based on the theoretical background, cognitive thinking, metacognition, problem-solving ability were set in the cognitive domain to develop appropriate test items. Based on the results of the KMO test (.903) and the Bartlett sphere test $(p<.05)$, the data is found to be suitable for factor analysis. The results of the first exploratory factor analysis revealed that the cognitive thinking and the metacognition were not distinguished but tied to each other. In the case of college students, the two concepts were distinguished. However, elementary school students could not clearly distinguish the two. The items that had low factor loading which was item 8 and 9 were deleted after review. In the end, as a result of exploratory factor analysis on the cognitive domain, 8 items of 'cognitive thinking and metacognition' and 5 items of 'problem-solving ability' were confirmed. The results of the second exploratory factor analysis of the cognitive domain are shown in Table 4.

Table 4. Exploratory Factor Analysis Result of Cognitive Domain

\begin{tabular}{ccc}
\hline & \multicolumn{2}{c}{ Components } \\
\hline & 1 & 2 \\
\hline Item 13 & .773 & .163 \\
\hline Item 14 & .730 & .168 \\
\hline Item 11 & .708 & .201 \\
\hline Item 12 & .699 & .231 \\
\hline Item 15 & .647 & .306 \\
\hline
\end{tabular}

\begin{tabular}{ccc}
\hline Item 6 & .092 & .719 \\
\hline Item 7 & .073 & .706 \\
\hline Item 3 & .213 & .679 \\
\hline Item 4 & .355 & .550 \\
\hline Item 2 & .365 & .534 \\
\hline Item 10 & .372 & .521 \\
\hline Item 5 & .314 & .453 \\
\hline Item 1 & .463 & .452 \\
\hline
\end{tabular}

Note: 1. Problem solving 2. Cognitive thinking-Metacognition

\section{Affective domain}

In the affective domain, three sub-factors which are intrinsic motivation, future-oriented motivation, and self-efficacy were set to develop appropriate items. Based on the results of the KMO test (.905) and the Bartlett sphere test $(p<.05)$, the data is found to be suitable for factor analysis. As a result of the first exploratory factor analysis of the affective domain, item 21 of future-oriented motivation showed more load on intrinsic motivation. Thus, the item was changed to a question for intrinsic motivation. The results of the second exploratory factor analysis of the affective domain are shown in Table 5.

\section{Behavioral domain}

The items for the behavioral domain were developed by setting three sub-factors of seeking help, managing physical environment, and time management. Based on the results of the KMO test (.874) and the Bartlett sphere test 
$(p<.05)$, the data is found to be suitable for factor analysis. As a result of the exploratory factor analysis of the behavioral domain, each item showed good factor loading. Therefore, we did not modify the items in the behavioral domain but decided to keep the original.

Table 5. Exploratory Factor Analysis Result of Affective Domain

\begin{tabular}{cccc}
\hline \multicolumn{4}{c}{ Components } \\
\hline & 1 & 2 & 3 \\
\hline Item 43 & .783 & .218 & .101 \\
\hline Item 41 & .781 & .196 & .058 \\
\hline Item 42 & .768 & .225 & .127 \\
\hline Item 45 & .721 & .193 & .234 \\
\hline Item 44 & .694 & .180 & .195 \\
\hline Item 38 & .246 & .836 & .079 \\
\hline Item 37 & .242 & .804 & .126 \\
\hline Item 36 & .198 & .752 & .106 \\
\hline Item 39 & .230 & .639 & .263 \\
\hline Item 34 & .124 & .116 & .709 \\
\hline Item 33 & .177 & .025 & .688 \\
\hline Item 32 & .029 & .138 & .665 \\
\hline Item 31 & .232 & .018 & .592 \\
\hline Item 35 & .035 & .245 & .558 \\
\hline Note: 1. Time management 2. Managing physical environment 3. Seeking help
\end{tabular}

Table 6. Exploratory Factor Analysis Result of Behavioral Domain

\begin{tabular}{cccc}
\hline \multicolumn{4}{c}{ Components } \\
\hline & 1 & 2 & 3 \\
\hline Item 29 & .797 & .146 & .069 \\
\hline Item 30 & .729 & .234 & .086 \\
\hline Item 26 & .700 & .156 & .309 \\
\hline
\end{tabular}

\begin{tabular}{cccc}
\hline Item 27 & .653 & .297 & .150 \\
\hline Item 28 & .648 & .283 & .144 \\
\hline Item 16 & .144 & .680 & .149 \\
\hline Item 20 & .229 & .653 & -.019 \\
\hline Item 21 & .145 & .611 & .351 \\
\hline Item 17 & .361 & .592 & .213 \\
\hline Item 19 & .363 & .570 & .208 \\
\hline Item 18 & .215 & .519 & .339 \\
\hline Item 24 & .076 & -.002 & .818 \\
\hline Item 22 & .146 & .246 & .704 \\
\hline Item 23 & .278 & .200 & .690 \\
\hline Item 25 & .097 & .314 & .554 \\
\hline Note: 1. Self-efficacy 2. Intrinsic Motivation 3. Future-oriented motivation
\end{tabular}

\section{Confirmatory Factor Analysis}

In order to verify the validity of the self-directed learning ability test, the research model was identified by confirmatory factor analysis for each of the three domains.

\section{Total domain}

The fit index of the research model $(3$ domains, 8 sub-factors) of the test for elementary school students is shown in Table 7 below.

Table 7. Fitness Indices for Self-directed Learning Ability Test

\begin{tabular}{cllllr}
\hline$\chi^{2}(p)$ & $d f$ & $N F I$ & IFI & CFI & RMSEA \\
\hline $1576.078(.000)$ & 808 & .824 & .906 & .905 & .043 \\
\hline
\end{tabular}

As shown in Table 7, although the fitness indices of NFI was under .09, IFI and CFI were above .90, and RMSEA was .043. Fitness indices shows overall positive results. The standardized regression coefficient for each item was also $.52 \sim .83$. The standardized regression coefficient for each item and sub-factor is shown in Figure 1.

Cognitive domain

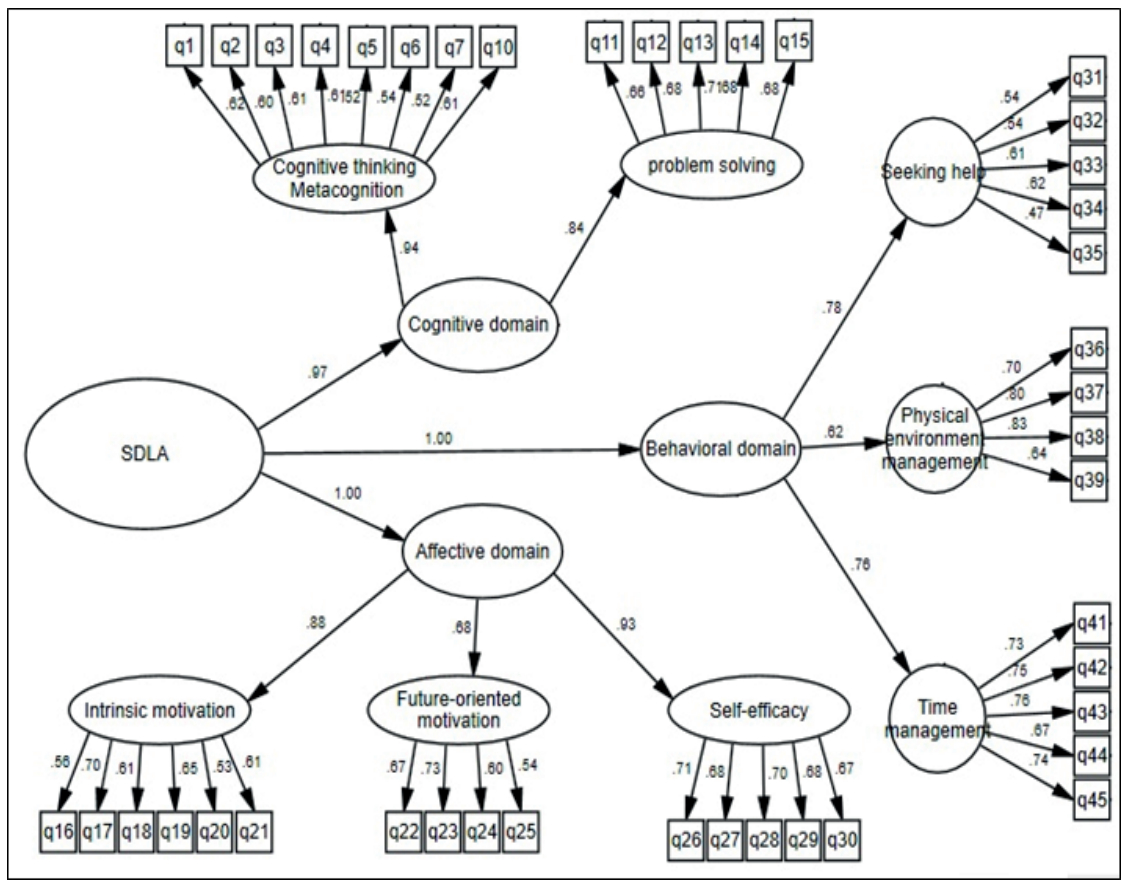

Figure 1. Structure of SDLA: Standardized Regression Coefficient by CFA 
The fitness indices of the cognitive domain of the self-directed learning ability test for elementary school students is shown in Table 8 below.

Table 8. Fitness Indices for Cognitive Domain

\begin{tabular}{cccccr}
\hline$\chi^{2}(p)$ & $d f$ & $N F I$ & IFI & CFI & RMSEA \\
\hline $119.3(.000)$ & 64 & .939 & .971 & .971 & .041 \\
\hline
\end{tabular}

As shown in Table 8, the fitness indices of $\mathrm{NFI}, \mathrm{IFI}$, and $\mathrm{CF}$ were all above .90, and RMSEA was .041, showing overall positive results. The standardized regression coefficient for each item was also $.51 \sim .72$. The standardized regression coefficient for each item in the cognitive domain is shown in Figure 2.

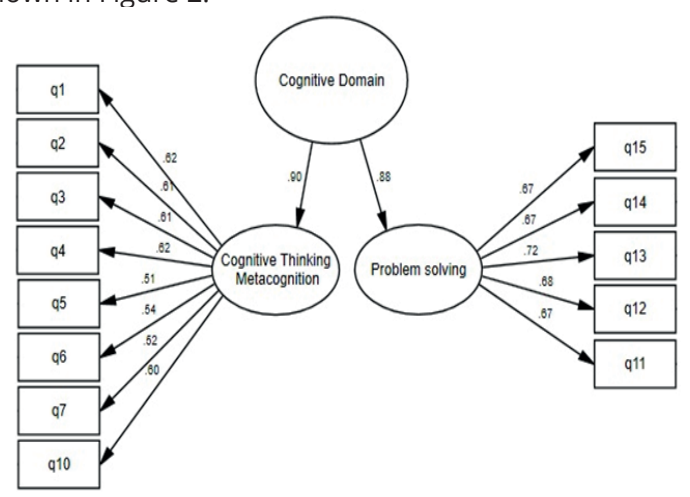

Figure 2. Confirmatory Factor Analysis Result for Cognitive Domain

Affective domain

The fitness indices of the affective domain in the hierarchical model of the self-directed learning ability test for elementary school students is shown in Table 9 below.

Table 9. Fitness Indices for Affective Domain

\begin{tabular}{cccccr}
\hline$\chi^{2}(p)$ & $d f$ & $N F I$ & IFI & CFI & RMSEA \\
\hline $267.3(.000)$ & 87 & .896 & .927 & .927 & .064 \\
\hline
\end{tabular}

As shown in Table 9, although the fitness indices of NFI was under .09, IFI and CFI were above .90, and RMSEA was .064. Fitness indices shows overall positive results. The standardized regression coefficient for each item was also $.51 \sim .71$. The standardized regression coefficient for each item in the affective domain is shown in Figure 3.

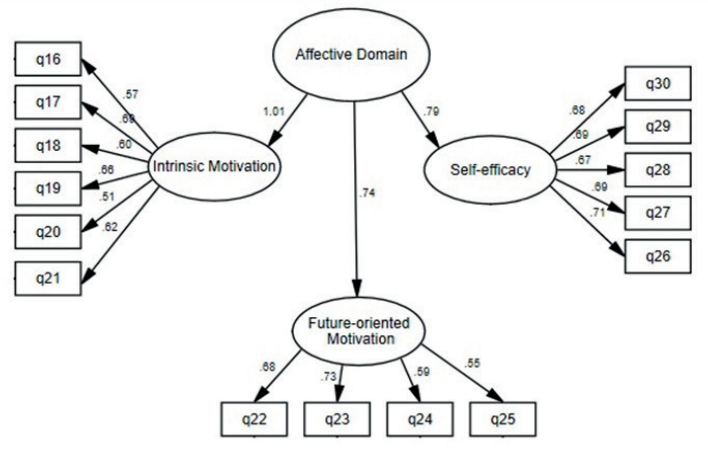

Figure 3. Confirmatory Factor Analysis Result for Affective Domain

\section{Behavioral domain}

The fitness indices of the behavioral domain in the hierarchical model of the test is shown in Table 10 below.

Table 10. Fit Indices for Behavioral Domain

\begin{tabular}{cccccr}
\hline$\chi^{2}(p)$ & $d f$ & $N F I$ & IFI & CFI & RMSEA \\
\hline $119.3(.000)$ & 64 & .939 & .971 & .971 & .041 \\
\hline
\end{tabular}

As shown in Table 10, the fitness indices of $\mathrm{NFI}, \mathrm{IFI}$, and CFI were all above .90 , and RMSEA was .060 , showing overall positive results. The standardized regression coefficient for each item was also $.48 \sim .83$. The standardized regression coefficient for each item in the behavioral domain is shown in Figure 4.

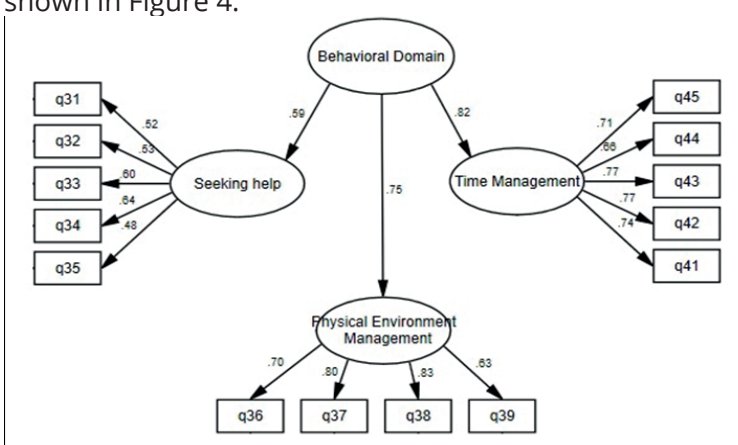

Figure 4. Confirmatory Factor Analysis Result for Behavioral Domain

Finalizing Items and Reliability

The finalized items and reliability after the analysis are shown in Table 11.

Table 11. Construct of finalized SDLAT

\begin{tabular}{|c|c|c|c|c|c|c|}
\hline Domain & Sub-factor & sample item & Items & $\begin{array}{l}\text { Item } \\
\text { number }\end{array}$ & $\begin{array}{r}\text { Reliabili } \\
\text { bac }\end{array}$ & ron- \\
\hline \multirow[t]{2}{*}{ Cognitive } & $\begin{array}{l}\text { cognitive thinking, } \\
\text { metacognition }\end{array}$ & $\begin{array}{l}\text { - I use appropriate study methods for each } \\
\text { subject. }\end{array}$ & 8 & $1 \sim 8$ & .799 & \multirow[t]{2}{*}{.868} \\
\hline & problem solving & - I can judge a problem objectively. & 5 & $9 \sim 13$ & .812 & \\
\hline \multirow{3}{*}{ Affective } & intrinsic motivation & $\begin{array}{l}\text { - I think it is important to achieve learning } \\
\text { goals. }\end{array}$ & 6 & $14 \sim 19$ & .776 & \multirow{3}{*}{.879} \\
\hline & future-oriented motivation & $\begin{array}{l}\text { - Even if I do not like subjects, I study if } \\
\text { necessary for the future. }\end{array}$ & 4 & $20 \sim 23$ & .733 & \\
\hline & self-efficacy & - I can learn well on my own. & 5 & $24 \sim 28$ & .817 & \\
\hline \multirow{4}{*}{ Behavioral } & seeking help & $\begin{array}{l}\text { - I ask a friend or teacher for help if I do not } \\
\text { know anything. }\end{array}$ & 5 & 29 33 & .685 & \multirow{3}{*}{.861} \\
\hline & $\begin{array}{l}\text { managing physical } \\
\text { environment }\end{array}$ & $\begin{array}{l}\text { - I set up the environment so that I can } \\
\text { study well. }\end{array}$ & 4 & $34 \sim 37$ & .824 & \\
\hline & time management & - I plan my time to study effectively. & 5 & $38 \sim 42$ & .850 & \\
\hline & \multicolumn{2}{|c|}{ Total } & 42 & $1 \sim 42$ & & .944 \\
\hline
\end{tabular}


The cognitive domain of the test which was finalized as in Table 11 above is composed of eight items of cognitive thinking and metacognition and five items of problem-solving ability. The reliability of sub-factors was .799 and .812 respectively. The affective domain consisted of six items of intrinsic motivation, four items of future-oriented motivation, and five items of self-efficacy. The reliability of sub-factors was $.776, .733, .817$. Finally, the behavioral domain consisted of five items for seeking help, four items of managing the physical environment, and five items of time management. The reliability of each sub-factor was $.685, .824, .850$. The reliability of the cognitive domain was .868 , the affective domain was .879 , and the behavioral domain was .861 . The reliability of the total items of the test was .944 .

\section{Discussion and Conclusions}

This study validated the self-directed learning ability test (SDLAT) for elementary school students to measure the learning ability required in future society. First, we analyzed the precedent research and classified the domain of self-directed learning ability into three domains of cognition, affection, and behavior. The sub-factors for each domain was selected for developing items. The developed items were then verified for its validity. The sub-factors of the cognitive domain were identified as 'cognitive thinking. metacognition' and 'problem solving'. The affective domain had 'intrinsic motivation', 'future-oriented motivation', and 'self-efficacy'. The behavioral domain had 'seeking help', 'managing physical environment', and 'time management'. In this study, the sub-factors of the cognitive domain were categorized into three factors: cognitive thinking, metacognition, and problem-solving ability. However, as a result of factor analysis, unlike college students, cognitive thinking and metacognition were identified as one integrated factor for elementary students. The sub-factors for the cognitive domain was also defined as learning ability, autonomous learning skills, and metacognition in the research by Lee (2008), but her research also integrated the autonomous learning skills and metacognition as one factor as the two cannot be distinguished clearly for elementary school students. This study showed similar results. This is due to the fact that elementary school students do not clearly distinguish the meaning of cognitive thinking and metacognition.

In the research carried out by Chung (2008), the self-controlling learning begins to be developed from senior years of elementary school and gradually differentiated in middle and high school. In the case of elementary school students, the three-dimensional hierarchical model was appropriate. However, in the case of middle school students, the cognitive strategy factor was differentiated. The high school students showed further differentiation from cognitive strategy and metacognition. As the learners grow older, the self-directed ability was differentiated further from general to specialize.

Therefore, in the subsequent studies, using the self-directed ability test developed on the basis of the similar theoretical background of this study, the learning ability of elementary to college students can be researched. By doing so, the integration of cognitive thinking and metacognition in the cognitive domain for elementary students can be explained. Whether it is a structural issue of the research or rooted in the development of learning ability for elementary school students.

The self-directed learning test for elementary school students, developed and validated in this study, is expected to be utilized not only to measure the ability but to im- prove it based on the result.

\section{References}

Ahn, D. H., \& Kim, Y. R. (2014). The relationship between self-directed learning, relatedness, self-concept, and academic achievement of Korean adolescents. Korean Journal of Educational Research, 52(1), 1-25.

Baik, K. S. (2011). The effects of self-directed learning program on self-directed learning ability, problem solving, and academic achievement for college students. The Journal of Education Research, 32(1), 77-95.

Brockett, R. G., \& Hiemstra, R. (1991). Self-direction in adult learning: Perspectives on theory, research, and practice. London, England: Routledge.

Browne, M, W., \& Cudeck, R. (1993). Alternative ways of assessing model fit. In K. A. Bollen, \& J. S. Long (Eds.). Testing structural equation models (pp.136-162). Newbury Park, CA: Sage.

Chung, M. K. (2002). The development and validation of self-regulated learning test for elementary school students. The Korean Journal of Educational Psychology, 16(4), 303-324.

Chung, M. K. (2003). The development of self-regulated learning test for secondary school students. Korean Journal of Educational Research, 41(4), 157-182.

Chung, M. K. (2005). The development of self-regulated learning test for university students. Journal of Education Evaluation, 18(3), 155-181.

Chung, M. K. (2008). The developmental changes of self-regulated learning. The Journal of the Korean Society for the Gifted and Talented, 7(2), 21-38.

Garrison, D. R. (1997). Self-directed learning: Toward a comprehensive model. Adult Education Quarterly, $48(1), 18-33$

Grow, G. (1991). Teaching learners to be self-directed: A stage approach. Adult Education Quarterly, 44(2), 109-114.

Guglielmino, L. M. (1977). Development of the self-directed learning readiness scale. Unpublished doctoral dissertation, University of Georgia.

Hong, S. H. (2000). The criteria for selecting appropriate fit indices in structural equation modeling and their rationales. Korean Journal of Clinical Psychology, 19(1), 161-177.

Hu, L. T., \& Bentler, P. M. (1998). Fit indices in covariance structure modeling: Sensitivity to underparameterized model misspecification. Psychological Methods, 3(4), 424-453.

Jung, H. S. (2004). The effect of topic-centered integrated learning program on the learning interest and the self-directed learning ability of elementary school children's. The journal of Elementary Education Studies, 11(2), 163-180.

Kim, A. Y. (2014). A key competency for future education: Self-directedness. The Korean Journal of Educational Psychology, 28(4), 593-617. 
Kim, E. J. (2014). An analysis of the structural relationship among achievement goal motivation, self-directed learning, self-efficacy and self-leadership of students. Journal of Learner-Centered Curriculum and Instruction, 14(12), 303-326.

Kim, J. H. (2004). The effects of study skills training program on self-directed learning attitudes and academic achievement of elementary school students. The journal of Elementary Education Studies, 11(1), 39-58.

Kim, S. H., Yim, H. R. \& Chung, I. J. (2015). Does self-direction in learning influence interpersonal relationships in addition to academic achievement?. Journal of Youth Welfare, 17(1), 305-332.

Kim-Cheong, C., Kim, K. S., Yoo, K. O., \& Yoo, G. H. (1996). A study on development of self-directed learning readiness scale for primary school teacher and its applications. Korean Journal of Adult \& Continuing Education, 2(1), 1-25.

Knowles, M. S. (1975). Self-directed learning: A guide for learners and teachers. New York: Association Press.

Lee, K. H. (2017). What should be the innovative teaching and learning methods for future talent? International Future Society \& KERIS (Korea Education \& Research Information Service (Eds.), Korea's Future Education Report of the Fourth Industrial Revolution Period (241-247). Paju: Kwnagmoongak.

Lee, S. J. Chang, Y. K., Lee, H. N., \& Park, K. Y. (2003). A study on the Development of Life-Skills: Communication, Problem Solving, and Self-Directed Learning. Seoul: Korean Educational Development Institute.

Lim, Y. O., \& Suh, K. H. (2017). Relationship between self-directedness and learning motivation in early adolescence: Focused on mediating effects of self-regulation. Korean journal of youth studies, 24(7), 215-234.

Oddi, L. F. (1986). Development and validation of an instrument to identify self-directed continuing learners. Adult Education Quarterly, 36, 97-107.

Park, H. K., \& Choi, S. W. (2014). The relationship among self-directed learning ability, meaning in life and happiness in elementary school teachers. The Journal of Lifelong Education and HRD, 10(2), 1-26.

Park, S. R., \& Son, E. Y. (2017). The effects of self-directed learning program for middle school student. The Korean Journal of Educational Methodology Studies, 29(3), 519-542.

Pintrich, P. R. \& De Groot, E. V. (1990). Motivational and self-regulated learning components of classroom academic performance. Journal of Educational Psychology, 82(1), 33-40.

Song, I. S. (2005). Self-regulated learning test for elementary school students. Seoul: Chang Media.

Stockdale, Susan L. \& Brockett, Ralph G. (2011). Development of the PRO-SDLS: A measure of self-direction in learning based on the personal responsibility orientation model. Adult Education Quarterly, 61(2), 161-180.
Zimmerman, B. J. \& Martinez-Pons, M. (1986). Development of a structured interview for assessing student use of self-regulated learning strategies. American Educational Research Journal, 23(4), 614628.

Zimmerman, B. J. \& Schunk, D. H. (2011). Self-regulated learning and performance: An introduction and an overview. In Zimmerman, B. J. \& Schunk, D. H. (Eds), Handbook of Self-Regulation of Learning and Performance. UK: Routledge. 